\title{
Reciprocal Learning in Mathematics Problem Posing and Problem Solving: An Interactive Study between Canadian and Chinese Elementary School Students
}

\author{
Aihui Peng ${ }^{1 *}, \mathrm{Li} \mathrm{CaO}^{2}$, Bo Yu ${ }^{1}$ \\ 1 Southwest University, CHINA \\ ${ }^{2}$ University of West Georgia, USA
}

Received 26 August 2020 - Accepted 24 September 2020

\begin{abstract}
The present study took a reciprocal learning approach to examine Canadian and Chinese elementary school students' $(N=40)$ mathematics problem posing and problem solving. Data included student performance, Skype meeting videos, meeting notes, and interviews transcripts through direct and indirect interactions between a pair of Canadian and Chinese sister schools. Qualitative and quantitative analyses show that the Chinese students and the Canadian students differed in the type of problems they posed to their counterparts, the performance of solving the problems posed by the counterparts, the strategies used to solve the problems, and the behavioral approach adopted to solve the problems. Possible sources of the differences and practical implications for mathematical teaching are discussed. The study proffered suggestions on what the Canadian and the Chinese can learn educationally from each other.
\end{abstract}

Keywords: cross cultural study, problem solving, problem posing, reciprocal learning

\section{INTRODUCTION}

In response to a growing and enthusiastic sense of education in a globalized environment, comparative studies witnessed a shift from cross-cultural comparison and competition to collaborative reciprocity (Cai, Mok, Reddy, \& Stacey, 2016). This new trend aimed at generating an awareness of the worldwide contexts in the pursuit of concrete educational experience that took place in school classrooms. Reciprocal learning underlines the value of equality among participants in different cultures. This approach recognizes that education and research often took place in charged competitive context of public, political, and international discussions, but highlights the importance of working together on the collaboratively defined practical school tasks (Connelly \& Xu, 2019). Different from the comparative studies in the traditional paradigm that aimed at providing a list of knowing that and knowing how, reciprocal learning purported the collaborative inquiry approach with an emphasize on doing this and doing that, and doing it this way and doing it that way (Connelly \& $\mathrm{Xu}, 2019)$. In this paper, we took the reciprocal learning approach to examine mathematics problem posing and problem solving of the Canadian and Chinese elementary school students, as part of a large partnership project between Canada and China.

\section{THEORETICAL BASES}

\section{Learning Mathematics through Problem Solving}

Problem solving is deemed as the very focus of school mathematics education around the world. Throughout the Standards, the NCTM (2000) asserted a link between problem solving and mathematical understanding:

\section{Problems and problem solving play an essential role in students' learning of mathematical content and in helping students make connections across mathematical content areas. ...Accordingly, much of the mathematics that students encounter can be introduced by posing interesting problems on which students can make legitimate progress. (p. 334)}

Not only is problem solving a means by which students can deepen their mathematical understanding, but also many students enjoy solving problems. As Lambdin (2003) observed, "learning mathematics through problem solving is engaging and rewarding" ( $p$. 


\section{Contribution to the literature}

- The study took a reciprocal learning stance to explore the commonalities and differences in problemsolving and problem-posing between Canadian and Chinese elementary school students who first posed mathematics problems to their counterparts and then solved the problems posed by their counterparts.

- The study provided a better understanding of the nature of elementary school students' problem posing, and its relation to problem-solving in the cross-cultural contexts.

- The study provided empirical evidence at the group/class-level to advance the continuous discussion of the East-West educational paradigms in mathematics education that often arises from the comparative studies.

11). Many students find problem solving to be more enjoyable than rote memorizing, or learning only by watching and listening to the teacher. In addition, students develop mathematical habits of mind through problem solving. Levasseur and Cuoco (2003) suggested, "Students develop these habits of mind as a byproduct of learning mathematics through problem solving" ( $p$. 27). Examples of such habits are guessing, challenging a solution by looking back, looking for patterns, analyzing a special case, and representing a problem in various ways. Furthermore, through problem solving students learn to become better problem solvers. Problem solving is a process starting from the minute students are faced with the problem until the end when the problem is solved. In his seminal work on problem solving, Polya (1945) proposed a four-phrase model of problem solving: understanding the problem, devising a plan, carrying out the plan, and looking back. Each phase was accompanied by a set of heuristics, or guidelines, to support the process. When students are given a problem for which they have no immediately apparent resolution, nor an algorithm that they can directly apply to get an answer, they must then read the problem carefully, analyze it for whatever information it has, and examine if they can come up with a strategy. This process forces the reorganization of existing ideas and the emergence of new ones as students work on problems.

Mathematics problems are the key in the teaching and learning of problem solving. According to the different purposes, researchers classified mathematical problems into different types. For instance, Yeo (2007) distinguished the mathematically rich tasks from the non-mathematically rich tasks. For the former focuses includes analytical tasks and synthesis tasks for students to learn new mathematics, such as problem-solving strategies, analytical thinking, metacognition and creativity. The latter includes procedural tasks and 'word problems' which a student practices what he or she has been taught earlier by the teacher. From the cognitive perspective, Stein, Grover, and Henningsen (1996) posited that different problems possess different features, incur varied cognitive demands on students, and thus offer different opportunities for classroom mathematics learning. They classified mathematical problems into two main categories: problems with low cognitive demand and problems with high cognitive demand. Mathematical problems with low cognitive demand require students to memorize, or reproduce facts, or to perform relatively routine procedures without making connections to the underlying mathematical ideas. Tasks with high cognitive demand require students to make connections to underlying mathematical ideas.

\section{Learning Mathematics through Mathematical Games}

Mathematical game problems are especially useful in developing problem solving in elementary mathematics classrooms. Firstly, games are engaging. Research continuously shows that mathematical games, as experienced by students, are highly engaging, generate more student-to-student mathematical discussions, and result in students spending more time 'on-task' compared with non-game activities (Bragg, 2012a). Next, mathematical games serve as effective pedagogical tools in primary mathematics instruction (Bragg, 2012b). As Russo and Russo (2020) observed, mathematical games were widely utilized in elementary school classrooms, with $85 \%$ of Australian elementary teachers incorporating games into their mathematics instruction multiple times per week. They also demonstrated how games could be the catalyst for rich mathematical investigations. Furthermore, designing games can support student learning. Cody et al. (2015) presented evidence that student experiences of designing mathematical games can support mathematical learning, and that mathematical game creation and play assists students in practicing newly-learned challenging concepts. Specifically, they found that topics learnt through students creating games led to equivalent performance on a standardized assessment compared with traditional instructional approaches, despite preprogram assessments suggesting the game design topics were more difficult. Mathematical games offer student a fun and engaging way to transform mathematic problems into investigations (Russo \& Russo, 2020).In the present study, we invited the $3^{\text {rd }}$ grade primary school students in Canada and China to first design their favorite mathematical game problems for their 
international peers, and then solve the mathematical game problems designed by their counterparts.

\section{Problem Posing and its Relatedness with Problem Solving}

Problem posing has long been recognized as a critically important intellectual activity in scientific investigation. However, compared with the wide concern of problem solving in both research and practice in mathematics education, problem posing had been neglected for a long time. However, recently, there is an increased interest in problem posing and significant advances have been made for placing problem solving at the heart of school mathematics (Ellerton, 2013). Research on problem solving has been focused on its nature including strategies and process of problem posing, its links with other aspects of mathematical ability including conceptual understanding, problem solving, and creativity, and its position in school curriculum as well as in teacher education programs and teacher professional development (e.g., Singer, Ellerton, \& Cai, 2015; Xie \& Masingila, 2017).

Silver (1994) defined problem posing as a cognitive activity of either re-formulating given problems or generating new problems that implies that problem posing could occur before, during or after problem solving. Existing studies on the relatedness between problem posing and problem solving verified the positive relationship between them, namely, good problem solver is usually a good problem poser, and vice versa. For instance, Ellerton (1986) found that the problems posed by able children were more complex than the problems posed by less-able children that provided evidences that problem posing and problem solving are closely related. Cai and his colleagues measured students' problem-posing and problemsolving performance using both tasks that were rarely related (Silver \& Cai, 1996) and they concluded that students' problem posing performance was closely related with their problem-solving performance. Kilpatrick (1987) provided a theoretical argument that the quality of the problems subjects pose might serve as an index of how well they can solve problems, and although there are a few empirical studies that have provided evidence for it. However, the questions on how students in different countries and regions pose mathematics problems and the differences in the magnitude of the relationship between problem solving and problem posing for students from different regions remain unanswered.

\section{Cross-cultural Comparison on Problem Posing and Problem Solving}

Among various international comparative studies, problem solving has become one of the focused research areas. This is due to the fact that the development of students' abilities to solve problems has remained as one of the fundamental goals and a staple of school mathematics education around the world (Stanic \& Kilpatrick, 1988). Studies in this area have revealed remarkable differences of students' mathematical thinking and reasoning in mathematical problem solving and problem posing across different cultural backgrounds and educational systems (Cai, 2004; Jiang, Hwang, \& Cai, 2014). For instance, in a series of studies to investigate U.S. and Chinese 6th grade students' thinking and reasoning in mathematical problem solving, Cai and his colleagues (Cai \& Silver, 1995; Cai, 2000; Huang \& Cai, 2010) found that U.S. and Chinese students differed markedly in the use of solution strategies and representations. The U.S. students frequently used visual or pictorial representations, while the Chinese students used symbolic representations more frequently. These studies also revealed a strong connection between the students' ability to solve problems and their ability to pose valid problems within the same mathematical context (Cai et al., 2013).

In their cross-national study on problem posing and solving for US and Chinese sixth grade students (Cai \& Hwang, 2002), the results showed that there was a stronger link between problem solving and problem posing for the Chinese sample, whereas the link was much weaker for the US sample. Posing a variety of problem types appeared to be strongly associated with abstract strategy use in the Chinese sample. Cai and Hwang indicated that the differential nature of the relationships for the US and Chinese students should not be interpreted as implying a lack of generality in the link between problem solving and problem posing. The observed differences in problem posing across regions, such as in the study of Cai and Hwang (2002), provided important ground for further research. Van Harpen and Sriraman (2013) followed this line of research and analyzed problem posing among students from the United States and from two distinct regions of China, and found differences that suggest a strong link between mathematical knowledge and problem posing success.

\section{Contributions of the Study}

As earlier comparative studies suggest (e.g., Cai \& Hwang, 2002; Cai et al., 2016; Jiang, Hwang, \& Cai, 2014), differences of students' thinking and reasoning in problem solving and problem posing reflect the varied learning opportunities in different educational systems. The present study extended this line of research by exploring similarity and differences in mathematics problem posing and problem solving of elementary school students from Canada and China where they were learning mathematics in two vastly different mathematics education systems. This cross-cultural approach would help with revealing general guidelines for mathematics education between the two counties, 
and identifying effective strategies in mathematics learning and instruction for classroom practice, as well.

Furthermore, the present study served as a specific case of the emerging trend in comparative studies of mathematics education that are shifting from crosscultural comparison and competition to collaborative reciprocity (Cai, Mok, Reddy, \& Stacey, 2016). More specifically in our case, reciprocity functioned at two levels. One the one hand, the reciprocity occurred across two groups of the Canadian and Chinese $3^{\text {rd }}$ grade elementary school students. Each group took turns to pose mathematical problem games that they designed for the other group, and then solved the mathematics games posed by their international peers. On the other hand, the reciprocity occurred at the individual student level. The participating students were first asked to design and pose his or her favorite problem to their international peers, and then each student had to face the challenges in solving the mathematical game problems posed by their counterparts. The task of posing and solving a mathematical problem asked for different sets of mathematical knowledge and skills from the students, and compelled them to play in different roles. This reciprocal collaborative process provided both the Canadian and Chinese students with equal and balanced opportunities to challenge, and to be challenged by, their international peers (Connelly \& Xu, 2019). At both the group and individual level, they were learning to work collaboratively in the problem posing and problem solving in mathematics.

Still, different from the previous studies that employed the survey questionnaire (e.g., Cai \& Hwang, 2019; Silver \& Cai, 1996), interview (Xie \& Masinglia, 2017) and static data, the present study used live sessions of the Reciprocal Learning Program for data collection. Observing the live sessions reinforced ecological validity of our data and allowed us to capture the content, strategy use, and behavior patterns of the $3^{\text {rd }}$ grade elementary school students as they were posing and solving mathematics problems. This naturalistic inquirybased approach enabled us to observe continuous interactions between two Canadian and Chinese elementary schools while they posed mathematics problems to their international peers and solved the problems posed by their counterparts (Peng, Ezeife, \& $\mathrm{Yu}$, 2018). The naturalist approach helped with capturing of doing this and doing that, and doing it this way and doing it that way (Connelly \& Xu, 2019) in mathematics problem solving and problem solving, which were often implicit in the previous cross-cultural comparative studies (Cai, Mok, Reddy, \& Stacey, 2016). With these conceptual and methodological considerations, the present study strove for a better understanding of mathematics problem solving and its link with mathematics problem posing in a crosscultural context.

\section{THE PRESENT STUDY}

\section{Set up of the Research Team in the Partner Schools}

It is commonly agreed that teacher-researcher partnerships could benefit from the accumulated learning of ordinarily isolated groups and create richer learning opportunities for more students (Cai, Morris, Hohensee, Hwang, Robison, \& Hieber, 2018). The present study was conducted in such a global context, as part of a large on-going project titled as Reciprocal Learning Partnership Project in teacher education and school education between Canada and China since 2014. The Project involved two Canadian and five Chinese universities, two Canadian School Boards and over forty Canadian and Chinese schools. Researchers from the participating universities have teamed up with elementary and secondary schoolteachers, administrators and district advisors to implement a long-term reciprocal learning relationship between schools in Canada and China. The Project has four research teams - the mathematics education team, general education team, teacher education team, and science education team. The mathematics education team includes two teams of researchers and "Sister Schools" in order to understand and compare the two systems in mathematics education. The present study reports the results from one of the research teams arising from interactions with principals and mathematics teachers from a pair of the third-grade classes in two "Sister Schools".

This pair of sister schools has been partnered since 2014. The Canadian school is located in Windsor, Ontario, Canada with 300 students enrolled in kindergarten up to grade 8 . The Chinese school is located in Chongqing, China. This public school enrolled 3000 students from junior Kindergarten to Grade 6. The school is a prestigious primary school in Chongqing. The pair of sister schools maintained regular synchronous and asynchronous interactions through various internet platforms, i.e., Skype, QQ, “WeChat", email communications, and telephone calls, as well as the Pepper Software system and Blackboard system. Once a year, the partnership allowed mathematics teachers, school administrators, and other delegates to visit their respective partner schools. The main interactions between the two sister schools were carried out primarily through monthly Skype meetings. During the meeting, researchers and teachers interacted on issues of mathematics education, including teaching resources, the use of textbooks, use of aids and manipulatives; preparation and use of lesson notes, lesson plans, student classroom behaviors and attitude to learning mathematics that raised by mathematics teachers of the 3rd grade from both Canadian and Chinese sister schools. So far, a total 30 Skype meetings have been conducted, and two of them were focused on 


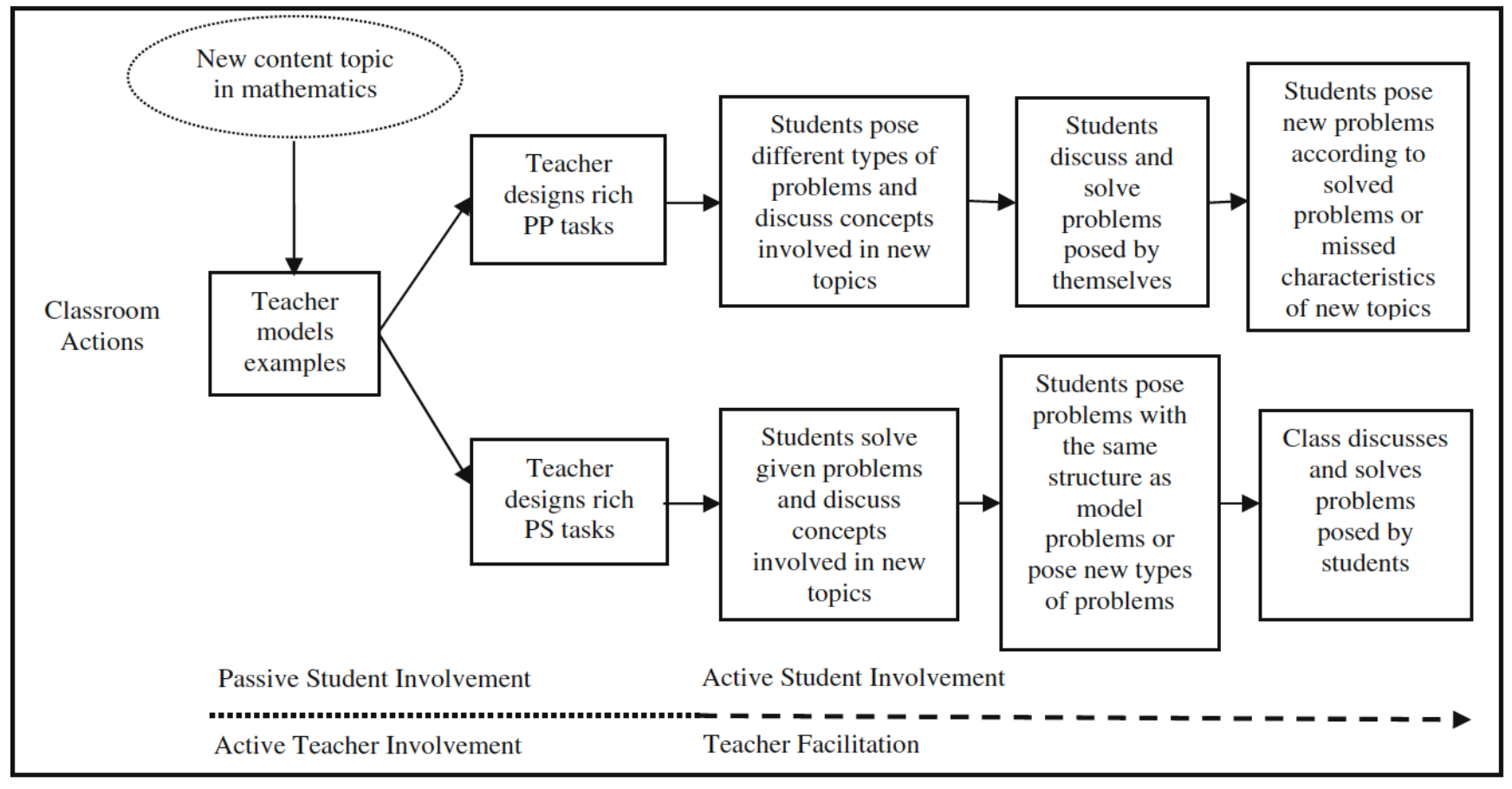

Figure 1. Extended Active Learning Framework

mathematical game problems and served as the main data resources for the present study.

\section{Guiding Framework}

The current study was guided by an Extended Active Learning Framework (Figure 1), which was revised from Ellerton (2013) by for continuously moving students from being passive receivers to active learners, and offering a promising direction for incorporating problem posing into instruction involving problem solving (Xie \& Masingila, 2017).

This framework provided opportunities of engaging learners in both problem posing and problem solving in a flowing way, as well as exploring potential interactions which happened between these two activities through the process.

According to the Extended Active Learning Framework, students would be initially engaged in solving model problems, then posing new problems, and finally solving their own posed problems. Both problem solving and problem posing are inquiry-based activities. They generally require time for students to understand the task, and then create and revise mental models back and forth. This framework provided a logic model and steps of the reciprocal learning activity in problem posing and problem solving between the Canadian and the Chinese elementary school students. They went through the process to select their favorite mathematical game problems, modify and pose the self-designed mathematics problems to the counterparts, watch and listen to how their counterparts solving the problems, and give feedback to them.

\section{Research Questions}

Our goal was to achieve a better understanding of different perspectives and practices of mathematics education in Canada and China, through observing an interactive process of problem of posing and problem solving between the Canadian and Chinese elementary school students. Specifically, we addressed three research questions: (1) What are the characteristics of the mathematics problems that the Canadian and Chinese elementary school students posed to their counterparts? (2) What are the strategies that the Canadian and Chinese elementary school students used to solve the mathematics problems posed by their counterparts?(3) Is there any difference in the approach to problem solving between the Canadian and Chinese elementary school students?

\section{METHODS}

\section{Participants}

A total of 40 third-grade students participated in the study, with 20 students from one Chinese elementary school and 20 students from one Canadian school. Students on both sides were further divided in two subgroups, with ten students participating in the first Skype meeting and the other ten students participating in the second Skype meeting.

\section{Data Collection Procedure}

The data were collected through two sources. The first source included video tapes of two Skype meetings 
Table 1. Types of the Mathematics Problems Posed by the Chinese and the Canadian Students

\begin{tabular}{lccccccccc}
\hline & \multicolumn{4}{c}{ Mathematics Problems Posed by } \\
Chinese students & \multicolumn{4}{c}{ Mathematics Problems Posed by Canadian } \\
students
\end{tabular}

Note: * Area of mathematics content in which the problems situated: Number Sense and Numeration (NN), Geometry and Spatial Sense (GS), Patterning and Algebra (PA), and Data Management and Probability (DP).

on the topic of mathematical game problems, with each session lasting for approximately one hour. The second source included focus group interviews with Chinese teachers to ascertain their views about the two Skype meetings.

Before the Skype meetings, the students in both the Canadian and Chinese third-grade classes were first asked to prepare their favorite mathematical game problem individually or by teamwork. Then, they were asked to present the self-made game problem to their classmates and mathematics teacher. Finally, the Chinese students and teacher voted for six mathematical game problems, while the Canadian students and teachers selected four mathematical game problems. In order to make it more feasible and appropriate, mathematics teachers from both sides helped students with wording and format of the mathematical game problems (see Appendix).

In the Skype meetings, the Canadian and Chinese students who originally proposed the selected mathematical game problems were asked to act as a "game play manager" to present the problems to their counterparts. On the other hand, the students who received the problem acted as "game players" to solve the problems posed by their counterparts. The Canadian and Chinese students swapped the role of a game play manager and a game player after each mathematical game problem. Both the Canadian and Chinese students used English to provide instructions, present, and solve the mathematical game problems.

In each Skype meeting, to reduce the language barriers, an English teacher helped the Chinese students with the English language when they had difficulty presenting the mathematical game problems and giving instructions to the Canadian students, and explaining the solution strategies to solve the mathematical game problems posed by the Canadian students. Similarly, a graduate student who spoke both Chinese and English sat with the Canadian students and helped with translation between the English and Chinese language.

\section{RESULTS}

\section{The Characteristics of the Mathematics Problems that the Canadian and Chinese Students Posed to their Counterparts}

To address Research Question 1, we looked at characteristics of the mathematical game problems that the Canadian and Chinese Students posed to their counterparts. These problems were classified in three dimensions. The first dimension focused on the content area in which the mathematical game problems were situated. To facilitate the classification of the mathematical game problems created by the Canadian and the Chinese students, the corresponding curriculum standards of Canada and China were used. Based on the Ontario Curriculum Grades 1-8: Mathematics (2005), the mathematical game problems posed by the Canadian students were classified in the category of: Number Sense and Numeration (NN), Measurement (M), Geometry and Spatial Sense (GS), Patterning and Algebra (PA), and Data Management and Probability (DP). Similarly, the Mathematics Curriculum Standards for Compulsory Education in China (Ministry of Education 2016), which included three strands, i.e., Numbers and Algebra, Shapes and Geometry, Statistics and Probability, were used to classify the mathematical game problems created by the Chinese students.

The second dimension of our classification examined connection of the problem to real-life situation i.e., whether the problem was situated in a real-life context or a non-real-life context. Finally, the third dimension of our classification looked at the level of cognitive demand of each mathematical game problem, i.e., whether it is a problem of low cognitive demand or high cognitive demand according to Stein and colleagues' classification (Stein, Grover, \& Henningsen, 1996).

As shown Table 1, the Chinese students posed six problems with two problems in Number Sense and Numeration, two problems in Geometry and Spatial Sense, one in Data Management and Probability, and one problem in Patterning and Algebra; whereas the Canadian students posed four problems all in one area, i.e., Number Sense and Numeration. Furthermore, three of the six problems that the Chinese students posed were situated in a real-life context, with one in Number Sense 
Table 2. Performance and Solution Strategies of the Canadian and Chinese Students in Solving the Mathematics Problems Posed by the Counterparts

\begin{tabular}{|c|c|c|c|c|c|c|c|c|c|c|}
\hline \multirow[b]{2}{*}{ Problem \# } & \multicolumn{6}{|c|}{$\begin{array}{l}\text { Mathematics Problems Solved by } \\
\text { Canadian students }\end{array}$} & \multicolumn{4}{|c|}{ Mathematics Problems Solved by Chinese students } \\
\hline & 1 & 2 & 3 & 4 & 5 & 6 & 7 & 8 & 9 & 10 \\
\hline Name of math game & $\begin{array}{l}\text { Card } \\
\text { game }\end{array}$ & $\begin{array}{l}\text { Cook } \\
\text { a cake }\end{array}$ & $\begin{array}{l}\text { Whichever } \\
\text { way wins }\end{array}$ & $\begin{array}{l}\text { Math } \\
\text { magic }\end{array}$ & $\begin{array}{l}\text { Paper } \\
\text { cutting }\end{array}$ & $\begin{array}{l}\text { Fold a } \\
\text { string }\end{array}$ & $\begin{array}{l}\text { Buzz, pop, } \\
\text { and fizz }\end{array}$ & $\begin{array}{l}\text { Find the initial } \\
\text { number }\end{array}$ & $\begin{array}{l}\text { Products } \\
\text { games }\end{array}$ & $\begin{array}{l}\text { The big } \\
\text { scoop }\end{array}$ \\
\hline Content area* & $\mathrm{NN}$ & NN & DP & GS & GS & PA & NN & NN & NN & NN \\
\hline Real-life context & No & Yes & No & No & Yes & Yes & No & No & No & No \\
\hline Level of cognitive demand & $\mathrm{L}$ & $\mathrm{H}$ & $\mathrm{L}$ & $\mathrm{L}$ & $\mathrm{L}$ & $\mathrm{H}$ & $\mathrm{L}$ & $\mathrm{H}$ & $\mathrm{L}$ & $\mathrm{L}$ \\
\hline Performance ${ }^{* *}$ & $\mathrm{~S}$ & $\mathrm{~N}$ & $\mathrm{~S}$ & S & $S$ & $\mathrm{~N}$ & $S$ & $S$ & $S$ & $S$ \\
\hline Strategies ${ }^{* * *}$ & $\mathrm{TE}$ & UDR & UM & UDR & US & LP & UM & UF & UM & UF \\
\hline
\end{tabular}

Notes: Area of mathematics content in which the mathematics problems situated: Number Sense and Numeration (NN), Geometry and Spatial Sense (GS), Patterning and Algebra (PA), and Data Management and Probability (DP); ** Problem Solved (S), Problem Not-solved (N); *** Trial and Error (TE), Use direct Reasoning (UDR), Look for a Pattern (LP), Use a Model (UM), Use a Formula (UF), Use Symmetry (US).

and Numeration, one in Geometry and Spatial Sense, and one in Patterning and Algebra; while none of the four problems that the Canadian students posed was real-life related. Finally, of the six problems that the Chinese students posed four fell in the low level of cognitive demand and two in high cognitive demand. In comparison, of the four problems that the Canadian students posed, three were low cognitive demand problems and one was in high cognitive demand.

\section{The Performance and Solution Strategies that the Canadian and Chinese Students Used in Solving the Mathematics Problems}

To address Research question 2, we examined the performance and solution strategies that the Canadian and Chinese students used in solving the mathematics problems that their counterparts posed. First, we examined students' performance according to whether they solved the problem (Solved) or not solved the problem (Not-Solved). As Table 2 shows, the Chinese students successfully solved the four problems in Number Sense and Numeration posed by the Canadian students. On the other hand, the Canadian students succeeded in solving the two problems in Geometry and Spatial Sense, one problem in Number Sense and Numeration, and one problem in Data Management and Probability posed by the Chinese students. However, they also did not solve one of the two problems of Number Sense and Numeration and one problem in Patterning and Algebra. Also shown in Table 2, the Canadian students succeeded in solving the three problems without real-life context and one of the three real-life related problems, but they did not solve two of three real-life related problems. Furthermore, the Canadian students succeeded in solving all four lowdemand mathematics problems, but they did not solve both high-demand problems posed by the Chinese students. In comparison, the Chinese students succeeded in solving all four mathematics problems posed by the Canadian students with three problems at the low-demand level and one problem at the highdemand level.

Then, we used Polya's (1949) list of reasonable ways to examine the problem solving strategies that the Canadian and the Chinese students used in solving the problems that their counterparts posed. Strategies on the list included: Guess and check, Look for a pattern, Make an orderly list, Draw a picture; Eliminate possibilities, Solve a simpler problem, Use symmetry, Use a model, Consider special cases, Work backwards, Use direct reasoning, Use a formula; Solve an equation, and Be ingenious.

As Table 2 shows, a total of six problem-solving strategies were used in the interactive Skype session, i.e., Trial and Error, Use direct Reasoning, Look for a Pattern, Use a Model, Use a Formula, and Use Symmetry. The Canadian students used five strategies to solve the six mathematics problems posed by the Chinese students, i.e., Trial and Error, Use direct Reasoning, Look for a Pattern, Use a Model, Use Symmetry. However, they did not use the strategies of Use direct Reasoning and Look for a Pattern to solve the problem Cook a Cake and Fold a String. In contrast, the Chinese students used two strategies to solve the four mathematics problems posed by the Canadian students, i.e., Use a Model and Use a Formula. As the vignette below shows, the Chinese students used a formula strategy to solve the problem: Find the initial number.

Canadian teacher: please give us an explanation of how did you get the answer?

Chinese student 1: 40 plus 25 equal to 65,65 divide by 10 get $6.5,6.5$ minus 1.5 equal 5 . So the initial number is 5 .

Canadian teacher: And then, use this formula to calculate other numbers, right?

Chinese Student 1: Yes! 
Table 3. Behavior differences of the Canadian and Chinese Students in Solving the Mathematics Problems Posed by the Counterparts

\begin{tabular}{lcccc}
\hline & \multicolumn{2}{c}{$\begin{array}{c}\text { Problems Posed by Chinese } \\
\text { students }\end{array}$} & \multicolumn{2}{c}{$\begin{array}{c}\text { Problems Posed by Canadian } \\
\text { students }\end{array}$} \\
\hline & 4 Math magic & 6 Fold a string & $\begin{array}{c}\text { 8 Find the initial } \\
\text { number }\end{array}$ & 10 The big scoop \\
\hline Cooperative or individual (Numbers of participants) & $1 \# 3$ & $1 \# 2$ & 6 & 4 \\
Give feedback (Underlying mathematical ideas) & No & No & Yes & Yes \\
\hline
\end{tabular}

As the vignette on solving the game problem Find the initial number clearly shows, the Chinese student uses addition and division step by step to get the final answer, a common formal strategy that the Chinese students used during problem solving.

\section{Behavior Differences during the Mathematics Problem Solving between the Canadian and Chinese Elementary School Students}

To address Research Question 3, we only relied on analysis of the Skype video to examine the approaches that the Canadian and Chinese students adopted in solving the problem posed by their counterparts. This analysis was to understand the differences during problem solving between the Canadian and Chinese students. Initially, we tried to follow Polya's (1949) fourstep model of mathematics problem solving to examine the process that the Canadian and Chinese students used to solve the mathematics problems. However, we found that Polya's model did not work well for our data. Then, we adopted a systematic qualitative data analysis procedure - the grounded theory approach (Corbin \& Strauss, 2015) - to code the data. This data based approach was deemed suitable because it rhymes with the research situation of our study that "explains an educational process of events, activities, actions, and interactions that occur over time" (Creswell, 2014, p. 432). Two researchers in our team watched the Skype video to examine the roles that the Canadian and Chinese students played both as game players and as managers. Video tape was paused and closely examined for any interesting and relevant moment. In addition, the Skype meeting notes were used to corroborate with the highlighted moment displayed on the Skype video. Coding categories were developed and crosschecked. Then the code categories were used to code the data by the two researchers. Data within each category were crosschecked and findings from different data sources were compared. We analyzed the data individually but discussed - and sometimes argued about - the findings until a mutually acceptable interpretation of the data was reached. After the initial analysis, we used the focus group interviews of the teachers to triangulate our findings.

Two recurring themes emerged in differences of student behaviors during the problem solving in our data analysis. The differences reflected in the types of problem solving and at the end of problem solving.
These two differences were coded as cooperative vs. individual problem solving and giving feedback for the problems. As Table 3 shows, for the four mathematics problems in the Skype video, the Chinese students worked individually, whereas the Canadian students worked cooperatively in teams of three or six. In the Math Magic, three Chinese students were present, but only one played a role in giving instruction for the problem. Similarly, in the scenario of Folding a string in which two Chinese students were present, only one student played the role for giving instruction. In contrast, when giving instruction and solving the problems, the Canadian students worked cooperatively as a team. In the problem of Find the initial number and The big scoop, there were six and four students present respectively, but each students played a special role. Our interview with the Chinese teacher also confirmed this finding:
"Yes, the difference is obvious. And we think it resulted from the different education backgrounds of the two countries. The difference also reflects the differences in teachers' conceptions of education and teaching behaviors. Based on this finding, we are trying to cultivate students' sense of cooperation in the classroom".

Table 3 further shows the differences of giving feedback at the end of problem solving between Canadian and Chinese students. The Canadian students gave feedback to their counterparts but the Chinese students did not provide feedback. For instance, after the Chinese students successfully solved the mathematics problem The Big Scoop, Canadian student summarized as "You can learn from this game: you can learn about estimation, subtraction, addition, make ten and carry on; it was fun because you never know how many squares you will get". For the game Find the initial number, although the Chinese students performed well, Canadian students still keeping on asking the Chinese students about the underlying mathematical ideas on how to solve it. In contrast, Chinese students did not give feedback (except yes or no) to their counterparts, whether they successfully solved the problem (Math magic), or were unable to solve the problem (Folding a string). 


\section{DISCUSSION AND CONCLUSION}

The present study examined the reciprocal process of problem posing and problem solving between two groups of $3^{\text {rd }}$ grade elementary school students from Canada and China. With the assistance of technology, the students from the two sister schools were able to overcome the barriers of time and distance, and conducted live class sessions to interact with each other through Skype. In the interactive Skype sessions, each group first posed mathematical game problems to the counterparts, and then solved the problems posed by the counterparts. The results revealed marked differences in content knowledge, thinking, reasoning, and behaviors in mathematics problem posing and problem solving between the students from two sister-schools in Canada and China.

\section{Mathematics Problems Posing of the Canadian and Chinese Students}

First, the two groups differed in the content area and the context of the problems that they posed to the counterparts. The mathematics problems posed by the Chinese students covered four different content areas, and half of these problems were situated in real-life contexts. In contrast, the mathematics problems posed by the Canadian students were concentrated in one content area, but none of these problems was related to a real-life scenario. More specifically, our findings suggest that the Chinese students may possess a wider range of knowledge in math content areas. They may be more familiar with problems in real-life contexts, while the Canadian students displayed knowledge in Number Sense and Numeration which was a focus of their mathematics curriculum at the $3^{\text {rd }}$ grade level (The Ontario Curriculum Grades 1-8: Mathematics 2005). Similar to problem solving, problem posing provides students with opportunities to explore fundamental mathematical concepts and ideas, such as the counting sequence, one-to-one correspondence, and computation strategies, etc. In addition, asking students to pose mathematics problem help students engage in a global meta-level activity which places high demands for students to activate prior knowledge and select appropriate strategies (Cai, 2004; Jiang, Hwang \& Cai, 2014). The task of posing a mathematics problem to their peers forced them to think in an alternative perspective in learning mathematics. This activity not only encouraged them taking responsibility for others, but also inspired them to reflect on their own math skills and learning experience. Observing the differences in mathematics problem posing between the two groups offers an alternative way to help students learning mathematics, improve teaching mathematics in the classroom, and assess curriculum implementation.
Performance and Strategies in Mathematics Problems Solving of the Canadian and Chinese Students

In regards to performance, the Chinese students solved all the mathematics problems posed by their counterparts, but Canadian students could not solve two of the six mathematics problems posed by the Chinese students. One problem was of Number Sense and Numeration, and the other was about Patterning and Algebra. Particularly, both of these problems were of cognitive demand and related to a real-life context. These findings show that the Chinese students performed better in solving mathematics problems of higher demand than the Canadian group. Consistent to the previous findings in math problem posing above, the performance difference in mathematics problem solving may be attributed to the fact that the Chinese students might possess more mathematics content knowledge than the Canadian students. Furthermore, the Chinese students should continue with working on the mathematically rich real-life problems, and the Canadian students could benefit from more exposure and training with mathematics problems of real-life tasks. Teachers in both countries could choose various types of rich tasks to assess their students' understanding, mathematical communication, and thinking process (Yeo, 2007).

Our findings also show the difference in strategy use between the Canadian and Chinese students. Our data show, the Canadian students used a wider variety of strategies in the solving the problems posed by the Chinese students, whereas the Chinese students mainly used two strategies, i.e., Use a formula or Use a model. Indeed, the difference in the strategy use might be impacted by the different types of problem that possessed different features of the problems; and therefore, called for different strategies for solution. A possible explanation of this difference might still be attributed to the differences of students' knowledge base. When students are more knowledgeable in the content and strategies, the problems become more familiar to them, so that they were more prone to recall prior experiences, activate the routines, and engage in effective ways to solve the problem. Our data suggest this might be the case for the Chinese students, particularly in their Use of a formula or Use a model to solve the problems posed by their Canadian peers.

Our results are consistent with Cai and his colleagues' findings that the U.S. and Chinese students differed markedly in the use of solution strategies and representations, and that the U.S. students frequently used visual or pictorial representations, while the Chinese students used symbolic representations more frequently (Cai, 1995, 2000; Hwang \& Cai, 2010). Similarly, in an earlier study to examine how the Canadian and Chinese teachers assessed students' problem solving strategies, we observed the influence of different approaches of mathematical teaching on 
students' mathematics problem solving (Peng, Ezeife, \& $\mathrm{Yu}, 2018)$. As our results show, the Canadian teachers highlighted an open and encouraging approach. They would invite students to discuss all possible methods, but refrained from suggesting the optimal methods. Instead, they would allow the students to decide and use the methods they like. In contrast, the Chinese teachers mentioned that they would discuss the advantages and disadvantages of various methods and give suggestions on when to use specific methods. The Canadian teachers' open and encouraging approach to teaching may have led to student use of different strategies, whereas the Chinese teachers' optimal methods approach may have led to fewer methods among their students.

\section{The Approaches to Mathematics Problems Solving of the Canadian and Chinese Students}

As our findings show, the Canadian and Chinese students adopted different approaches to solving the mathematics problems. The Canadian students took a cooperative approach and worked as a group in solving the problems, whereas the Chinese students solved the problems individually on his/her own. This finding is consisting with the results of our earlier study in a different situation conducted in the same project (Peng, Ezeife, \& Yu, 2018). In that study, we found that when given a mathematical problem, the Chinese students tended to solve it individually, while the Canadian students would get together and solve it in a cooperative way. The importance of cooperative play and learning for the young child's development was highlighted over a hundred years ago (Dewey, 1897). Ever since, this approach remains to be a highly recommended strategy for student learning, for it involves students in the active exchange of ideas rather than passive learning (Cai, Moyer, Wang, Hwang, Nie, \& Garber, 2013). Research has demonstrated the potential of cooperative problem solving in enhancement of young children's cognitive development and learning (Cai, Mok, Reddy, \& Stacey, 2016). Our results suggest that Chinese students need to learn from their counterpart on how to develop a cooperative way to solve problems. Similarly, the Chinese mathematics teachers need to work on creating a collaborative environment in the classroom to promote teamwork and collaborative learning.

In addition, our data revealed different behavior patterns between the Canadian and Chinese students at the end of problem solving process. One such difference pointed to a pattern that the Canadian students tended to give feedback to their Chinese peers at the end of playing each mathematics game to solve the problem. On the other hand, the Chinese students were merely focused on presenting and explaining how they solved the problem without giving feedback to their Canadian peers. This feedback-giving behavior pattern reflected the cooperative approach and the individual approach of problem solving that the Canadian and the Chinese students adopted in their respective problem solving process. It was logic and natural to see the Canadian students' feedback giving behavior aligned with their cooperative team working approach to problem solving. When they were trying to communicate with the Chinese students, they simply extended this teamwork approach of problem solving to their Chinese peers. Similarly, it was not a surprise to see the Chinese students' not providing feedback to the Canadian students, for it fits their individual approach to problem solving. The Chinese students tended to believe the task was to solve the problem and therefore, their task was completed when the problem was solved. This finding bears significant implications in mathematics teaching and learning, particularly for China.

According to Polya's (1945) model of problem solving, finding a solution does not mean the end of the problem solving process. In fact, the fourth step of Polya's model is for problem solvers to examine the obtained solution of a problem by checking the argument along the way. In our study, the Canadian students' feedback matched with the step that allowed them to articulate why the mathematics game worked to them, and how the problem could be solved. Articulating and communicating how and why mathematics works plays a critical role in students' development of mathematical thinking (Eisenhart, Borko, Underhill, Brown, Jones, \& Agard, 1993). The Chinese students may have implicitly fulfilled this forth step in their individual approach, but they definitely missed the opportunity to openly share their thinking process and communicate how and why they solved the problems with the Canadian peers. Both the Chinese students and mathematics educators can benefit from adopting a cooperative team approach to mathematics problem solving. The team-work approach would help engage students in a more interactive way of problem solving, develop their habit to work with others, and share experience of problem solving and learning the mathematics. This teamwork approach would promote understanding, mathematical communication, and thinking process in mathematics education (Yeo, 2007).

\section{Limitations and Suggestions for Further Research}

We set out to take a reciprocal learning approach to bring the Partnership Canada-China inquiry into the realm of explorations of problem posing and problem solving between the Canadian and Chinese elementary school students from cultural perspective. Our collaborative study revealed the remarkable differences of students' performance, reasoning, and behaviors between the two groups, and pointed to the plausible reasons why such differences exited, which have addressed what the Chinese might learn educationally from Canada and what the Canadian can learn educationally from the Chinese. However, our results should be used with caution due to the limitations of the 
study, for our data came primarily from two Skype meetings of mathematical game problems. Although these live sessions offered rich data and displayed live interactions between the Canadian and Chinese students, the content coverage was limited to ten mathematical games of problem posing and problem solving between two small groups of students in Canada and China. Apparently, the coverage of mathematics content and our observations were limited. In addition, this study involved a relatively small sample with only $403^{\text {rd }}$ grade elementary school students from two counties. We intend to continue with this line of research along with the ongoing project of Reciprocal Learning in Teacher Education and School Education between Canada and China ( $\mathrm{Xu} \&$ Connelly, 2019), and involve more students from both Canada and China in a subsequent investigation to reinforce the results and report them in the short term. Furthermore, we plan to adopt a holist approach and use a multiple-methods design to explore more research topics and over a longer period of time. More specifically, our next step was to examine the relatedness of problem posing and problem solving at the intersection of both cognitive and affective factors. We plan to carry out this research through a collaboration of education administrators, teachers, and students in the two sister schools and their related communities. We are confident that with effort more data will emerge to help us better understand mathematics problem posing and problem solving among students in both countries. Such data will help to build a two-way learning bridge and enable us to glean sights in improving mathematics education in both countries.

\section{ACKNOWLEDGEMENTS}

We would like to express our sincere gratitude to the two anonymous reviewers for their valuable comments and suggestions which led to substantial improvement of the manuscript. Their insights and generous assistance in providing relevant references are greatly appreciated.

The researchers gratefully acknowledge the grant from the Social Sciences and Humanities Research Council (SSHRC) of Canada which funds the larger Reciprocal Learning Canada-China Partnership Project (Xu \& Connelly, 2019), on which this mathematicsfocused study is based. The support of the National Social Science Foundation in China (17XMZ032), which also partially funded the study, is also hereby appreciated. The authors appreciate the support and contributions from graduate students in both Canada and China and are grateful to all the Canadian and Chinese students, teachers, and school administrators for their participation and support in this project.

\section{REFERENCES}

Bragg, L. A. (2012a). The effect of mathematical games on on-task behaviours in the primary classroom. Mathematics Education Research Journal, 24(4), 385401. https:/ / doi.org/10.1007/s13394-012-0045-4.

Bragg, L. A. (2012b). Testing the effectiveness of mathematical games as a pedagogical tool for children's learning. International Journal of Science and Mathematics Education, 10(6), 1445-1467. https:/ / doi.org/10.1007/s10763-012-9349-9

Cai, J. (2000). Mathematical thinking involved in U.S. and Chinese students' solving process-constrained and process-open problems. Mathematical Thinking and Learning, 2, 309-340. https://doi.org/ 10.1207/S15327833MTL0204_4

Cai, J. (2004). Why do U.S. and Chinese students think differently in mathematical problem solving? Exploring the impact of early algebra learning and teachers' beliefs. Journal of Mathematical Behavior, 23, 135-167. https:/ / doi.org/10.1016/j.jmathb.2004.03. 004

Cai, J., \& Hwang, S. (2002). Generalized and generative thinking in U.S. and Chinese students' mathematical problem solving and problem posing. The Journal of Mathematical Behavior, 21, 401421. https:/ / doi.org/10.1016/S0732-3123(02)00142 $-6$

Cai, J., \& Hwang, S. (2019 in press). Learning to teach through mathematical problem posing: Theoretical considerations, methodology, and directions for future research. International Journal of Educational Research. https://doi.org/10.1016/j.ijer.2019.01.001

Cai, J., \& Silver, E. A. (1995). Solution processes and interpretations of solutions in solving a divisionwith-remainder story problem: Do Chinese and U.S. students have similar difficulties? Journal for Research in Mathematics Education, 26(5), 491-497. https://doi.org/10.5951/jresematheduc.26.5.0491

Cai, J., Mok, I. A.C., Reddy, R., \& Stacey, K. (2016). International comparative studies in mathematics: Lessons for improving students' learning. New York: Springer. https://doi.org/10.1007/978-3-31942414-9_1

Cai, J., Morris, A., Hohensee, C., Hwang, S., Robison, V., \&Hieber, J. (2018). Building and structuring knowledge that could actually improve instructional practice. Journal for Research in Mathematics Education, 49(3), 238-246. https://doi.org/10.5951/jresematheduc.49.3.0238

Cai, J., Moyer, J. C., Wang, N., Hwang, S., Nie, B., \& Garber, T. (2013). Mathematical problem posing as a measure of curricular effect on students' learning. Educational Studies in Mathematics, 83(1), 57-69. https:/ / doi.org/10.1007/s10649-012-9429-3 
Cody, K. J., Rule, A. C., \& Forsyth, B. R. (2015). Mathematical game creation and play assists students in practicing newly-learned challenging concepts. Creative Education, 6(14), 1484. https:/ / doi.org/10.4236/ce.2015.614149

Connelly, F. M., \& Xu, S. (2019). Reciprocal learning in the partnership project: Fromknowing to doing in comparative research models. Teachers and Teaching: Theory and Practice, 25(6), 1-20. https:/ / doi.org/10.1080/13540602.2019.1601077

Corbin, J. M., \& Strauss, A. (2015). Basics of qualitative research: Techniques and procedures for developing grounded theory (4th Ed.). Los Angeles, California: SAGE Publications Inc.

Creswell, J. W. (2014). Educational research: Planning, conducting, and evaluating quantitative and qualitative research (5th Ed.). Upper Saddle River, New Jersey: Pearson Education, Inc.

Dewey, J. (1897). Speech to Parents of Dewey School. In K. Mayhew, \& A. C. Edwards (Eds.). The Dewey School: The laboratory school of the University of Chicago 1896-1903. NY: Atherton, 1966.

Eisenhart, M., Borko, H., Underhill, R., Brown, C., Jones, D., \& Agard, P. (1993). Conceptual knowledge falls through the cracks: Complexities of learning to teach mathematics for understanding. Journal for Research in Mathematics Education, 24, 8-40. https://doi.org/10.5951/jresematheduc.24.1.0008

Ellerton, N. F. (1986). Children's made-up mathematics problems - A new perspective on talented mathematicians. Educational Studies in Mathematics, 17, 261-271. https:/ / doi.org/10.1007/BF00305073

Ellerton, N. F. (2013). Engaging pre-service middleschool teacher-education students in mathematical problem posing: Development of an active learning framework. Educational Studies in Mathematics, 83, 87-101. https://doi.org/10.1007/s10649-012-9449$\mathrm{Z}$

Huang, R., \&Cai, J. (2010). Implementing mathematical tasks in US and Chinese Classrooms. In Y. Shimizu, B. Kaur, R. Huang, \& D. Clarke (Eds.), Mathematical tasks in classrooms around the world (pp. 145-164). Rotterdam: Sense Publishers. https://doi.org/ 10.1163/9789460911507_009

Jiang, C., Hwang, S., \& Cai, J. (2014). Chinese and Singaporean sixth-grade students' strategies for solving problems about speed. Educational Studies in Mathematics, 87, 27-50. https://doi.org/10.1007/ s10649-014-9559-x

Lambdin, D. V. (2003). Benefits of teaching through problem solving. In F. K. Lester (Ed.), Teaching mathematical through problem solving: Prekindergarten-Grade 6 (pp. 3-13). Reston, VA: National Council of Teachers of Mathematics.
Levasseur, K., \& Cuoco, A. (2003) Mathematical habits of mind. In H. L. Schoen (Ed.), Teaching mathematics through problem solving: Grades 6-12 (pp. 27-37). Reston, VA: National Council of Teachers of Mathematics.

Ministry of Education. (2016). Mathematics curriculum standards for compulsory education in China. Beijing: The People's Education Press.

National Council of Teachers of Mathematics (NCTM). (2000). Principles and standards for school mathematics. Reston, VA: Author.

Ontario. (2005). The Ontario curriculum, grades 1-8: mathematics. Ontario: Toronto Publication.

Peng, A, Ezeife, A. N., \& Yu, B. (2018). Reciprocal learning in mathematics education: An interactive study between two Canadian and Chinese elementary schools. Comparative and International Education / Éducation Comparée et Internationale, 47(1), Article 4.

Polya, G. (1945). How to solve it. Princeton, NJ: Princeton University Press. https://doi.org/10.1515/ 9781400828678

Russo, J., \& Russo, T. (2020). Transforming mathematical games into investigations. Australian Primary Mathematics Classroom, 25(2), 14-19. https:// doi.org/10.29333/iejme/5843

Silver, E. A., \& Cai, J. (1996). An analysis of arithmetic problem posing by middle school students. Journal for Research in Mathematics Education, 27(5), 521-539. https:// doi.org/10.5951/jresematheduc.27.5.0521

Singer, F. M, Ellerton, N. F, \& Cai, J. (2015). Mathematical problem posing: from research to effective practice. New York, NY: Springer. https:/ / doi.org/10.1007/9781-4614-6258-3

Silver, E. A., Leung, S. S., \& Cai, J. (1995). Generating multiple solutions for a problem: A comparison of the responses of U.S. and Japanese students. Educational Studies in Mathematics, 28(1), 35-54. https://doi.org/10.1007/BF01273855

Stanic, G. M. A., \& Kilpatrick, J. (1988). Historical perspectives on problem solving in mathematics curriculum. In R. I. Charles \& E. A. Silver (Eds.), Research agenda for mathematics education: The teaching and assessing of mathematical problem solving (pp. 1-22). Reston, VA: National Council of Teachers of Mathematics.

Stein, M. K., Grover, B. W., \& Henningsen, M. (1996). Building student capacity for mathematical thinking and reasoning: An analysis of mathematical tasks used in reform classrooms. American Educational Research Journal, 33(2), 455488. https:/ / doi.org/10.3102/00028312033002455

Van Harpen, X. Y., \& Sriraman, B. (2013). Creativity and mathematical problem posing: An analysis of high school students' mathematical problem posing in 
China and USA. Educational Studies in Mathematics, 82(2), 201-221. https://doi.org/10.1007/s10649012-9419-5

Xie, J., \& Masingila, J. O. (2017). Examining interactions between problem posing and problem solving with prospective primary teachers: A case of using fractions. Educational Studies in Mathematics, 96, 101118. https:/ / doi.org/10.1007/s10649-017-9760-9
Xu, S., \& Connelly, M. (2019). Partnership Grant Reciprocal learning in teacher education and school education between Canada and China. https://doi.org/ 10.1080/13540602.2019.1659766

Yeo, J. B. (2007). Mathematical tasks: clarification, classification and choice of suitable tasks for different types of learning and assessment. Report No. ME 200702, Nanyang Technological University, Singapore.

\section{APPENDIX}

Mathematical Game Problems that the Canadian and the Chinese Students Posed to Their Counterparts

\begin{tabular}{|c|c|c|}
\hline$\#$ & Name & Description \\
\hline 1 & Card games & $\begin{array}{l}\text { Make it } 24 \text {, choosing } 4 \text { cards from the pile, use different strategies to make Chinese } \\
\text { the four number } 24 \text {. You can use plus, times, minus, and division. }\end{array}$ \\
\hline 2 & Cook a cake & $\begin{array}{l}\text { Students show that one pan can only cook two cakes a time. Cooking one Chinese } \\
\text { side needs one minute. How many minutes needed to cook } 3 \text { cakes? }\end{array}$ \\
\hline 3 & $\begin{array}{l}\text { Whichever Way } \\
\text { Wins }\end{array}$ & $\begin{array}{l}\text { Students use spinners to get a number and move forward or backward } \\
\text { with the number students get. Who first arrives at } 20 \text { wins. }\end{array}$ \\
\hline 4 & Math magic & $\begin{array}{l}\text { Put the paper with triangle, square, parallelogram, rectangle shapes into } \\
\text { an envelope, and choose one shape randomly and show part of it. } \\
\text { Students are expected to guess the shape. }\end{array}$ \\
\hline 5 & Paper Cutting & $\begin{array}{l}\text { Symmetrical practice. This game is designed for students to understand Chinese } \\
\text { the beauty of being symmetrical. Chinese traditional paper cutting is well } \\
\text { integrated into math. }\end{array}$ \\
\hline 6 & $\begin{array}{l}\text { Folding the } \\
\text { string }\end{array}$ & $\begin{array}{l}\text { Students show that fold the string twice and cut from the middle part. } \\
\text { How many pieces will you get? }\end{array}$ \\
\hline 7 & $\begin{array}{l}\text { Buzz, Pop, and } \\
\text { Fizz }\end{array}$ & $\begin{array}{l}\text { If the number is the multiple of three, the number will be called Fizz. If the Canadian } \\
\text { number is the multiple of four, it will be called Pop. If the number is the } \\
\text { multiple of five, it will be called buzz. Students stand forming a circle and } \\
\text { a student start to utter a number. The following student will make the } \\
\text { number plus one. If the number belongs to one of the special groups } \\
\text { (mentioned above), the students need to call the number fizz, pop or buzz. }\end{array}$ \\
\hline 8 & $\begin{array}{l}\text { Find the initial } \\
\text { number }\end{array}$ & $\begin{array}{l}\text { Students choose one number from } 1 \text { to } 10 \\
\mathrm{X} \text { times } 2=\mathrm{X} 1 \\
\mathrm{X} 1 \text { plus } 3=\mathrm{X} 2 \\
\mathrm{X} 2 \text { times } 5=\mathrm{X} 3 \\
\mathrm{X} 3 \text { minus } 25=\mathrm{X} 4 \\
\text { Tell the } \mathrm{X} 4 \text { to another student who do not the initial number. The student } \\
\text { will guess the initial number with } \mathrm{X} 4 \text {. }\end{array}$ \\
\hline 9 & Products games & $\begin{array}{l}\text { Get } 4 \text { products in a row (horizontal, vertical or diagonal) by moving a } \\
\text { maker to the factors to four products. }\end{array}$ \\
\hline 10 & The Big Scoop & $\begin{array}{l}\text { One student gives a number to another student. The students will estimate Canadian } \\
\text { the number and scoop manipulatives from the box. Another student will } \\
\text { use } 10 \text {-frame to check the exact number of the scooped manipulatives. } \\
\text { Then, students will compare the number with the initial number. }\end{array}$ \\
\hline
\end{tabular}

